\title{
Electron Microscopy Study of Zinc Silicate Coated Diatom Frustules
}

\author{
T. Gutu, ${ }^{*}$ D.-H. Lee, ${ }^{* *}$ C. Jeffryes, ${ }^{* *}$ G. L. Rorrer, ** C. Chang, ${ }^{* *}$ and J. Jiao.* \\ * Department of Physics, Portland State University, Portland, OR 97201, USA \\ ** Department of Chemical Engineering Oregon State University, 102 Gleeson Hall \\ Corvallis, OR 97331-2702, USA
}

We have developed a novel bioengineering paradigm to fabricate $\mathrm{Mn}^{2+}$-doped zinc silicate $\left(\mathrm{Zn}_{2} \mathrm{SiO}_{4}: \mathrm{Mn}\right)$ with controllable optoelectronic properties using diatom frustules as templates. The use of these templates makes the optoelectronic properties tunable and also preserves the diatom morphology [1]. In this report, we present the results of electron microscopy characterization of the bioengineered Pinnularia- $\mathrm{Zn}_{2} \mathrm{SiO}_{4}: \mathrm{Mn}$. It is expected that a systematic investigation of correlations between the fabrication conditions and the formation of the Pinnularia- $\mathrm{Zn}_{2} \mathrm{SiO}_{4}: \mathrm{Mn}$ nanomaterials will lead to an understanding of the formation mechanism and to the eventual control of their optoelectronic properties.

Zinc silicate was formed by thermal annealing of zinc chloride chemically deposited on diatom frustules. The zinc chloride particles were deposited on the surface of diatom frustules by heating the frustules in aqueous $\mathrm{ZnCl}_{2}$ solution activated by $\mathrm{Mn}^{2+}$ (aq). TEM and SEM specimens were carefully prepared by dispersing the diatom- $\mathrm{Zn}_{2} \mathrm{SiO}_{4}: \mathrm{Mn}$ in methanol. A couple of drops were then placed onto a TEM grid or Al stub using a micropipette. Electron microscopy characterizations were performed by a Tecnai F-20 field emission HRTEM/STEM/EDX at $200 \mathrm{keV}$ and a FEI Sirion FESEM at $30 \mathrm{keV}$.

Fig. 1a shows a girdle view TEM image of an intact diatom Pinnularia $s p$. frustule that is $35 \mu \mathrm{m}$ long and about $13 \mu \mathrm{m}$ wide. Its central area is slightly constricted. The zinc silicate coating of the frustules is not uniform (Fig. 2b). The coating was integrated into the diatom frustules in two fundamental ways. In some areas the frustules were coated as nanoparticles (Fig. 1b) and in other areas the frustules were coated as a thin film (Fig. 2a). Results suggest that the thin film coating is best achieved with a high concentration of the aqueous $\mathrm{ZnCl}_{2}$ solution. The original morphology of the diatom Pinnularia sp. was preserved during the coating process as shown in Fig. 1b, $2 \mathrm{a}$ and $3 \mathrm{~b} 1$. Unlike physical deposition technique which would block the pores after coating, this method does not cover the pores (areolae) of the diatom frustules (Fig. 1b, 2a and 3b1). Fig. 1c shows that the black nanoparticles are zinc silicate particles. The diffraction pattern shows that the structure of the coated frustules is polycrystalline (Fig. 2c). Fig. 3a depicts the surface morphology of an intact Pinnularia $s p$. frustule. A slightly deflected raphe end and parallel striae are clearly visible in the inset. EDX mapping and EDX nanoprobe analysis (Fig. 3b1-2 and Fig. 3c respectively) reveal that $\mathrm{Zn}$ is an integral part of the thin film coating. A study of the optoelectronic properties of the bioengineered diatom semiconductor materials is in progress.

References

[1] G. Rorrer, C. Chang, S. Liu, J. Clayton. J Jiao, J, Hedberg,Nanotech 5 (2005) 41-49. 
[2] This research is supported by the NSF's program of Nanoscale Interdisciplinary Research Team (NIRT). Award No. BES-0400648.
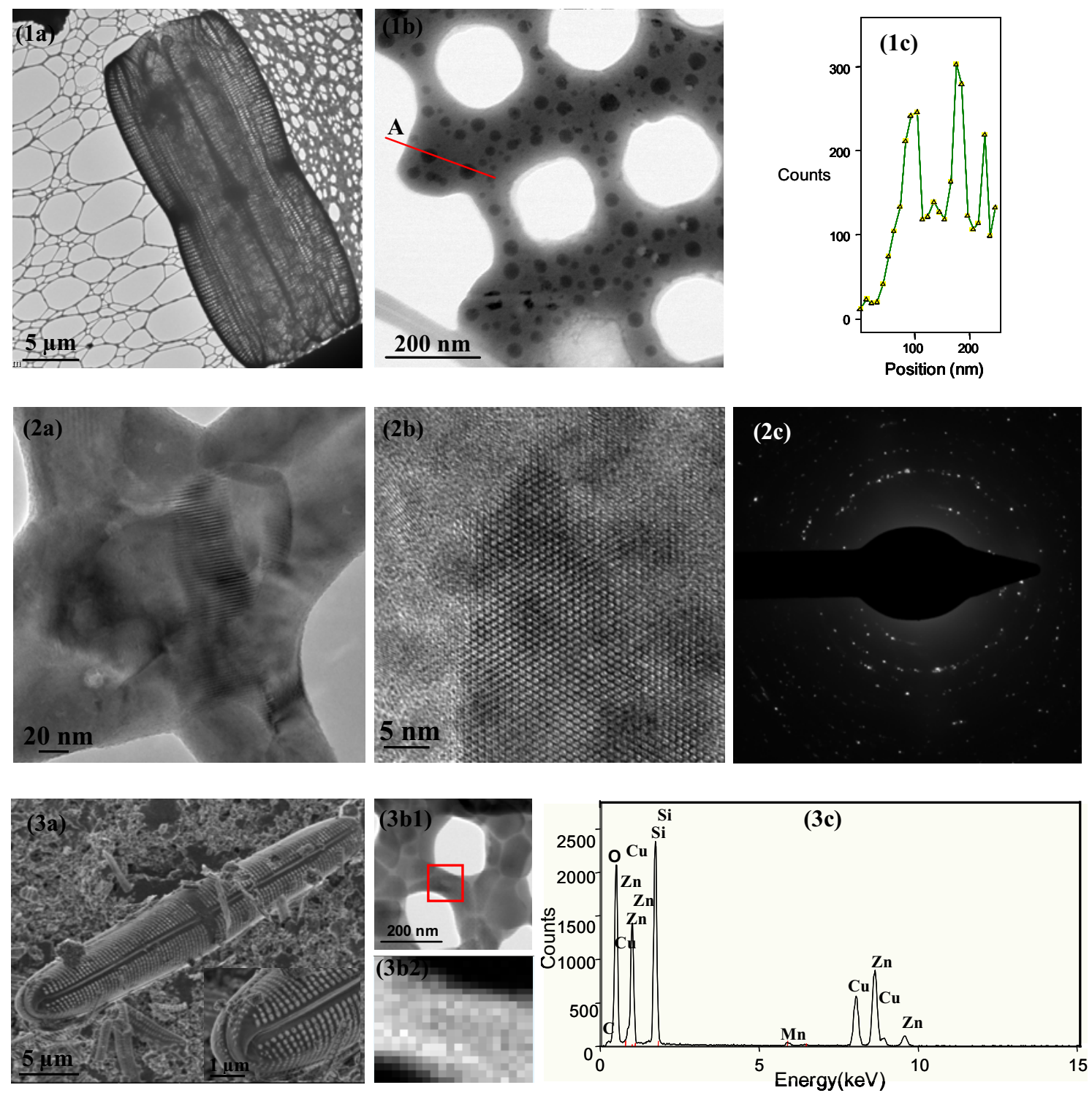

Fig. 1 (a) TEM image of diatom Pinnularia sp. (b) STEM image of diatom deposited with Zn.

(c) EDX line spectrum obtained from (b) showing the distribution of $\mathrm{Zn}$ along line A.

Fig. 2 (a)-(b) HRTEM image showing lattice fringes of $\mathrm{Zn}_{2} \mathrm{SiO}_{4}$ thin film in the (001) plane.

(c) Diffraction pattern of diatom frustule with $\mathrm{Zn}_{2} \mathrm{SiO}_{4}$ coating.

Fig. 3 (a) SEM image of diatom Pinnularia sp (Insert: Magnified distal end of the diatom).

(3b1) STEM image of diatom with $\mathrm{Zn}_{2} \mathrm{SiO}_{4}$ coating (Rectangle shows mapped area).

(3b2) EDX map of the surface of a diatom frustule in (3b1), showing distribution of $\mathrm{Zn}$

(White color shows presence of $\mathrm{Zn}$ ). (3c) EDX spot spectrum showing the chemical composition of the diatom with $\mathrm{Zn}_{2} \mathrm{SiO}_{4}$ coating ( $\mathrm{Cu}$ is an artifact of the TEM grid). 